\title{
Redes de gobernanza y organizaciones que intervienen en la gestión pública del agua en la esfera local: comités de agua potable del municipio de Xalatlaco, México
}

\author{
Gloria Jovita Guadarrama Sánchez ${ }^{1}$ \\ Colegio Mexiquense \\ Esmeralda Pliego Alvarado ${ }^{2}$ \\ UNAM
}

\begin{abstract}
Artículo científico
Material original autorizado para su primera publicación en el Journal de Ciencias Sociales, Revista Académica de la Facultad de Ciencias Sociales de la Universidad de Palermo.
\end{abstract}

Recibido: 18-11-2016

Aceptado: 21-2-2017

Resumen: El objetivo de este artículo es explorar la gestión de la provisión de agua, mediante el examen de un caso particular de arreglos de gobernanza, en el que intervienen actores gubernamentales, privados y sociales. El estudio se sustenta en investigación documental y de campo, está focalizado en el municipio de Xalatlaco, México; y sigue la idea de que los procesos de inclusión y exclusión al agua están condicionados por la forma que asumen los arreglos de gobernanza interna y externa de la red de organizaciones que participan en la gestión del recurso. La exploración muestra que las organizaciones gestoras son espacios de gobernanza que determinan el acceso al agua.

Palabras clave: gobernanza, redes, gestión pública, Comités de Agua Potable.

\section{Governance networks and organizations working in water public management at local spaces: Community Committees in Xalatlaco municipality, México}

\begin{abstract}
The aim of the study is to explore the management of water provision, through the analysis of a particular case of governance arrangements with participation of government, private and social players, focussed in the municipality of Xalatlaco, México. The analysis is supported with documental and field research and follows the idea
\end{abstract}

\footnotetext{
${ }_{1}^{1}$ Profesora investigadora en El Colegio Mexiquense A. C. Correo electrónico: ggloriags@prodigy.net.mx

2 Magíster en Ciencias Sociales. Correo electrónico: epliegoa@gmail.com
} 
that water inclusion and exclusion processes at local areas are established for the configuration of inner and external governance network arrangements of organizations participating in the resource management. The deliberation shows that community Committees are spaces of governance that determines water access.

Key words: governance, networks, public management, safe water committees.

\section{Introducción}

En nuestros días el agua se ha vuelto un recurso escaso y su disponibilidad para satisfacer las necesidades de las poblaciones se ha convertido en un reto para los gobiernos, que han sido obligados a transformar las estrategias de política pública y modificado las interacciones entre las instituciones, organizaciones y grupos que intervienen en la provisión, manejo y regulación del recurso. En el caso mexicano, David Barkin advertía, desde hace tiempo, que el sistema de gestión hídrica en México sufría una crisis severa, porque aun cuando las autoridades aseguraban que el 90\% de la población tenía acceso al agua potable y una parte un poco menor disponía de conexiones al alcantarillado, la realidad era que el país estaba sufriendo grandes estragos por la insuficiente disponibilidad del recurso en calidad y cantidad (Barkin, 2006). Paralelamente, otros estudios coinciden en que el involucramiento de la población en los problemas y en las decisiones para atenderlos contribuye a mejorar la gestión del agua (Amaya, 2010; Guerrero, 2010). Se advierte que en el caso mexicano la gestión del agua sigue dos vertientes: por una parte, existen organismos públicos integrados a las administraciones municipales que son los responsables de la provisión del servicio y, en otra vertiente, es manejada por organizaciones comunitarias. ${ }^{3}$ A partir de ese marco, en este texto se examina la gestión del agua en un caso municipal de intervención de organizaciones ciudadanas denominadas Comités de Agua Potable, con una mirada que considera que los procesos de inclusión-exclusión al agua están condicionados por la forma en la que se tejen los arreglos de gobernanza interna y externa, en la red de organizaciones que participan en la gestión del recurso.

Metodológicamente se utiliza el estudio de caso como forma de rescatar la particularidad que se vive en el municipio; se recurre a la noción de gobernanza como marco analítico para los sistemas de coordinación no jerárquicos en el sentido utilizado por Huffty que "[....] se refiere a los procesos colectivos, formales tanto como informales, que determinan, en una sociedad, como se toman decisiones y se elaboran normas sociales con relación a los asuntos públicos" (Hufty, 2008, p. 7), enfoque que identifica y construye componentes de la gobernanza. El análisis, focalizado en el municipio de Xalatlaco en el Estado de México, se apoya en investigación documental que da cuenta de la visión normativa y de los registros oficiales del municipio, y en investigación cualitativa, a través de entrevistas semiestructuradas a los representantes de los Comités de Agua Potable, regidores y autoridades. Se recabó información de todos los Comités en operación y se aplicó también una encuesta a grupos de pobladores sobre las prácticas para el acceso y uso del recurso en cuatro dimensiones: autonomía política, autonomía económica,

\footnotetext{
${ }^{3}$ Legalmente, la gestión del agua corresponde al municipio. No obstante, las formas comunitarias tradicionales de gestión no se han modificado en buena parte del país.
} 
mecanismos de sanción y vigilancia, y mecanismos de acceso. Con esos elementos se identifica a los actores y se traza, a través del análisis de redes sociales (ARS), un perfil de las relaciones en la red de organizaciones, asociada a los componentes de los arreglos de gobernanza. ${ }^{4}$

La exposición se estructura en cuatro apartados: en el primero se efectúa una breve revisión de los conceptos de gobernanza y redes y se comentan los componentes que guían la propuesta analítica; en el segundo se presentan las características del caso particular de estudio; en el tercero se examina la composición de la red, los actores que participan y los arreglos de gobernanza; el texto cierra en el cuarto apartado con las reflexiones derivadas del estudio.

\section{Gobernanza y redes}

Existen diferentes conceptos de gobernanza. Hufty (2008) advierte, a partir de los usos del concepto, la posibilidad de tres grupos de enfoques: uno, como sinónimo de gobierno; otro, como marco normativo, y uno más, como marco analítico para los sistemas de coordinación no jerárquicos. En este último, la gobernanza es no solamente un objeto de estudio, sino un método analítico que puede construir modelos y categorías analíticas (Hufty, 2008, pp. 7,9$)^{5}$

En la perspectiva de Ostrom, orientada a explicar los problemas que reviste la acción colectiva, los apropiadores de un recurso común pueden desarrollar arreglos de gobernanza y autorregulación para obtener mejores resultados. Los arreglos se estructuran a partir del contexto que incluye la estructura ecológica, sociopolítica y económica (Poteete, Janssen y Ostrom 2012, p. 70). Los mecanismos de estos arreglos están conformados a través de redes, organizaciones y relaciones entre los actores. La gobernanza de los comunes, como es el caso del agua, se conforma como un sistema policéntrico que involucra a actores privados y públicos: el Estado, el mercado y las organizaciones sociales. Muchos sistemas de gobernanza auto-organizados son invisibles, y se componen de un gran número de elementos activos, cuyos patrones de interacción poseen propiedades emergentes no fáciles de predecir. Se les percibe como un conjunto de normas y de agentes que interactúan y se adaptan a través de una modificación dinámica de sus normas, con base en la experiencia (Ostrom, 2014, p. 18).

La gobernanza es también una corriente de cambio en la gestión pública, asociada a la adopción de nuevos paradigmas de gobernabilidad, coordinación y relación entre el Estado y la sociedad como una forma distinta de conducir el gobierno (Aguilar, 2010; Fleury, 2002). En opinión de Lascoumes y Le Galès: "La gobernanza se entiende como un proceso de coordinación de actos, de grupos sociales, de instituciones para alcanzar objetivos discutidos y definidos colectivamente" (2014, p. 28). Los enfoques vinculados a la gobernanza surgieron como respuesta a las

\footnotetext{
${ }^{4}$ El análisis de redes es una herramienta para el mapeo de las relaciones que utiliza la ubicación de los actores para trazar vínculos relacionales entre las distintas posiciones. En el análisis subyace la idea de que los patrones de las relaciones inciden en la conducta de los actores. En el estudio se utilizó un solo tipo de software, Ucinet 6.85, en un análisis general simple de los vínculos entre los actores.

${ }^{5}$ El marco analítico de Hufty consta de cinco categorías analíticas: Los problemas; los actores; los puntos nodales; las normas; los procesos (Hufty, 2008, p. 9).
} 
preocupaciones para reformar el gobierno a la luz de la crisis financiera y de legitimidad del Estado benefactor, que dio lugar a la generación de nuevas formas de enfrentar los problemas, expresadas en cambios en el sistema, la organización y la estructura de los gobiernos, así como en la participación de los ciudadanos en las políticas públicas. Se coincide en que implica asumir que las estrategias de política pública requieren de la participación de redes de ciudadanos y organizaciones de la sociedad; lo que apunta a sociedades multicéntricas en las que la decisión, la ejecución, la evaluación y el control de la acción pública se organiza mediante relaciones más horizontales, que favorecen la diversidad y el diálogo, o bien, como formas compartidas de cogobierno (Fleury, 2002; Rhodes, 2007; Aguilar, 2010).

Así, entre las distinciones que marcan la gobernanza destaca que el conjunto de interacciones es entendido como sistemas de redes que no tienen un centro único o jerárquico para la toma de decisiones; una red se constituye cuando existen patrones relativamente estables de relaciones que vinculan a diversos actores en torno a un problema público. La gobernanza es entonces una forma diferente de ordenamiento y regulación de la acción pública, resultado de acuerdos colectivos, que contempla la interacción en red de actores públicos, privados, organizaciones sociales y comunitarias. (Blanco y Gomá, 2003). Las redes se integran por grupos de tres o más organizaciones que trabajan juntas, no solamente para lograr metas propias, sino metas colectivas y objetivos comunes; se componen de organizaciones relativamente autónomas y se pueden entender mejor como arreglos cooperativos (Provan y Kenis, 2008, p. 231).

Estos elementos aportan las pautas por las que discurre el análisis de la gestión del agua; la operacionalización de los conceptos divide los arreglos en gobernanza interna y externa, y utiliza como categorías analíticas: los actores, los nodos de la red, los mecanismos de inclusión- exclusión y la vinculación de las organizaciones con su entorno.

\subsection{Gobernanza interna y externa}

Para conocer cómo se estructura la gobernanza resulta útil considerar dos vías: la primera de ellas referida como gobernanza interna, alude a las relaciones que se establecen en cada una de las organizaciones o nodos de la red con sus miembros; la segunda denominada como gobernanza externa, remite a la relación de las organizaciones con otras organizaciones y con su entorno. Las dos vías se consideran ligadas, de modo que las relaciones de gobernanza interna interactúan e inciden con el funcionamiento general de la red.

Cabe notar que estas distinciones no están claramente establecidas en las interacciones de las organizaciones, se efectúan solamente para clarificar el modo en que operan las redes. Se puede decir que la gobernanza interna establece las condiciones para el funcionamiento de cada organización, la posición de los actores y las reglas que la articulan como un subsistema; en tanto que la gobernanza externa implica establecer relaciones con actores externos 
e involucrarse con los objetivos y con el modo general de operación de la red, a modo de arreglos para lograr metas comunes.

Al explorar la gobernanza interna es necesario observar el papel de los órganos directivos o patronatos en fijar la dirección de cada organización, en el tipo de relaciones y en las formas de manejar los recursos, su desempeño e integración, y considerar que se ha registrado un desplazamiento en la estructura jerárquica de las organizaciones y en las decisiones de arriba hacia abajo, que ha pasado de la gobernanza tradicional de las directivas a la gobernanza de redes (Laville, Young y Eynaud, 2015). Es preciso ver cómo se mueven los grupos de interés, los actores y la forma en la que obtienen apoyo de otras fuentes. Así, la gobernanza refiere al control interno de la organización y a los lazos que se establecen con el entorno, con relaciones de interdependencia y competencia por los recursos o por los bienes que constituyen el patrimonio de las organizaciones.

Los conceptos referidos implican no sólo el reconocimiento de la pluralidad de actores, sino su integración en marcos de interacción comunes desde los cuales intercambian recursos, negocian prioridades y toman decisiones relacionadas con proyectos públicos compartidos. Por lo que para este estudio se consideran centrales tres rasgos de la gobernanza (Blanco y Gomá, 2003):

- "La no existencia de un centro jerárquico capaz de fijar procesos de gobierno de manera monopólica...

- La interdependencia...

- Una cierta institucionalización, en el sentido menos estructural del término. Es decir, la existencia de interacciones más o menos sostenidas con algún nivel de estabilidad y rutinización" (Blanco y Gomá, 2003, p. 17).

Particularmente, se considera adecuado el enfoque analítico de la gobernanza para estudiar el caso de la red municipal gestora del agua, dado que está constituida como un sistema de coordinación no jerárquico, en el que los centros de decisión pueden multiplicarse, con capacidad para auto-organizarse y potencialidad para generar sus propias normas, que al mismo tiempo pueden operar de manera coherente. La red se conforma de organizaciones, constituidas en las localidades, que son en mayor o menor medida autónomas, percibidas como ámbitos decisionales y operativos; cada nodo toma sus propias decisiones, integrándose al funcionamiento de la red en su conjunto. Igualmente, se estima pertinente aplicar el análisis de redes para examinar la posición de los actores y el sentido de las relaciones. En esa visión, no se deja a un lado que las organizaciones pueden, asimismo, tener dueños o líderes que se apropian de las decisiones y que hacen de los organismos gestores espacios de poder que condicionan los procesos de inclusión-exclusión en el acceso al agua. Entre las consideraciones preliminares destaca el supuesto de que las determinaciones no son únicas, ni centralizadas, los protagonistas, lugares y esquemas operativos son diversos y por lo tanto asumen un carácter discrecional e inequitativo. 


\section{La red del Comité Central de Agua Potable de Xalatlaco}

Xalatlaco es una municipalidad ubicada en el Estado de México, 50 kilómetros al sureste de la Ciudad de México, 32 kilómetros al suroeste de la Ciudad de Toluca y 75 kilómetros al noroeste de la Ciudad de Cuernavaca; es uno de los 22 municipios de la zona metropolitana de Toluca (IGECEM, 2015), y es considerado como periférico y eminentemente rural, por lo tanto, con una amplia disponibilidad de suelo (Venancio e Iracheta, 2015, p. 114). Es también un municipio densamente poblado que cuenta con 18 comunidades con una población total de 26.865 habitantes, (INEGI, 2010); en términos generales ha tenido mayor crecimiento poblacional a partir de $2005 ; 34.7 \%$ del mismo es generado por incremento de la infraestructura carretera y la venta de vivienda a bajo precio debida a la lejanía del centro metropolitano, afectando los recursos naturales. Las actividades económicas principales son la construcción de vivienda, la extracción de madera y la fabricación de mobiliario.

En el Municipio se presentan dos tipos de tenencia de la tierra: la comunal y la propiedad privada, $75.29 \%$ de los terrenos corresponden a la propiedad privada y $24.70 \%$ a la propiedad comunal -comprendida por los bosques, ríos, barrancas, llanos y pastizales. La problemática en materia de tenencia y uso del suelo es extensa, debido a que la mayoría de la población no tiene regularizada su propiedad. La población ubicada en áreas urbanas y suburbanas alcanza una proporción del 69\% y en espacios rurales el 31\% (Seduv, 2003). ${ }^{6}$

Existen problemas de coordinación intergubernamental para la gestión integrada del recurso hídrico y se percibe el impacto sobre los recursos acuíferos resultado de la urbanización del municipio como parte del desarrollo de la zona metropolitana de Toluca (Venancio e Iracheta, 2015). Se han detectado asentamientos poblacionales irregulares, que generan desequilibrios administrativos, sociales y ambientales para la provisión de agua; los pobladores se ubican en lugares no autorizados o que no se contemplan en la planeación del municipio; se demandan de servicios en lugares inviables para su prestación y existe un alto índice de infracciones a los ordenamientos municipales. Adicionalmente, la irregularidad en la tenencia de la tierra genera especulación económica que es fuente de conflicto entre propiedad privada y comunal.

En lo que corresponde a los recursos naturales, existen importantes recursos acuíferos como consecuencia de la presencia de abundantes zonas forestadas, las cuales son almacenes naturales de aguas pluviales que producen humedecimiento profundo, con escurrimientos subterráneos y superficiales que dan origen a múltiples manantiales, principalmente en las partes media y occidental del municipio. Se cuenta con 29 manantiales de capacidad variable en los distintos puntos del territorio. Los manantiales son: Axochipan (Agua de las rosas), Yecapanteopa, Apapaxco, El Cedro, Atezcapa, El Pozo, Hueyatlaco, Puente de la Fábrica, La Fábrica Vieja, Agua de Lobos, El Pozo de Mezapa, El

\footnotetext{
${ }^{6}$ Durante el siglo pasado, México experimentó una transformación territorial y poblacional a gran escala, pasó de ser un país principalmente rural a uno predominantemente urbano. En los años cincuenta, poco más de la mitad de la población nacional residía en localidades menores de 2,500 habitantes, mientras que al inicio del nuevo milenio dos de cada tres mexicanos viven en zonas urbanas (SEDESOL, 2010).
} 
Cuandre, Tlilac, Pozoco, Tomasquillo, Dos Barrancas, Xoyatepetl, Acaxaco, Agua de Pájaros, Horno Viejo, Picachos, Agua Grande, Agua Chica, Canales, Cadena, Tlaxipehualapa, Vinotero, y Cuernito. Existe un río con cuatro afluentes que nace en la cabecera municipal, así como el río Agua Grande en la zona boscosa; adicionalmente, en el territorio existen pequeños caudales pluviales. Entre los problemas relevantes de la zona se encuentran la degradación de las fuentes, la sobreexplotación del recurso y las dificultades para el acceso al agua potable. ${ }^{7}$ El municipio no forma parte del sistema Lerma que provee de agua a la Ciudad de México, pero es el primer municipio cuyas corrientes tributan a esa cuenca y por ello su condición afecta la calidad y cantidad de agua que va a una amplia región metropolitana. Los manantiales que se encuentran en la cabecera municipal, utilizados intensivamente para el consumo, son cinco, el más importante, que alimenta la mayor parte de la red de agua potable, es el de Las canoas; se suman los manantiales: Axochilpan, Apapaxco, Atexcapa Yecapanteopa.

\subsection{Los Comités y el Sistema de Provisión de Agua Potable}

Los manantiales alimentan sistemas de agua potable que constituyen la infraestructura en forma de redes de distribución que proveen de agua a las comunidades conformando unidades o nodos de gestión manejados por organizaciones comunitarias denominadas Comités Autónomos de Agua Potable (CAAP). Es decir, el sistema mayor de aprovisionamiento de agua está integrado para su operación por organismos comunitarios manejados por agrupaciones ciudadanas locales. Los CAAP se integran administrativamente con cuerpos directivos conformados generalmente por un presidente, secretario, tesorero y vocales; en la práctica esta estructura es adaptada a las necesidades de la comunidad con variaciones en el número de personas que representan a la población. La Red del Comité Central de Agua Potable de Xalatlaco es un conglomerado integrado a un comité central, constituido desde 1982, que se encarga de convocar a los distintos comités gestores y de servir de vínculo con el gobierno municipal. ${ }^{8}$ El comité central fue establecido mediante el acuerdo de los 26 comités comunitarios que recibían agua por bombeo, para crear el sistema de agua más importante del municipio, el sistema Cuauhtémoc el cual es la base de la red objeto de esta exploración. El hecho de que el comité central que coordina la red haya estado en funciones a lo largo de más de tres décadas evidencia la existencia de patrones institucionalizados de intercambio, prácticas operativas y de comunicación, que han sido aceptados por la población como parte de la gestión pública del agua y cuya adaptación ha permitido su permanencia a lo largo de los años.

En comunidad son elegidos los integrantes de cada comité, a través de una asamblea de vecinos. Entre sus atribuciones se encuentra el cobro a los usuarios por la prestación del servicio que se efectúa mensual o anualmente.

\footnotetext{
${ }^{7}$ A modo de ejemplo, la degradación de los acuíferos es visible principalmente en el centro de la población; el río Xalatlaco se transformó en el punto de descarga del drenaje y es receptor de tiraderos de basura clandestinos que se encuentran en las orillas, lo que origina mal olor, focos de infección, proliferación de insectos y roedores (Ayuntamiento de Xalatlaco, 2009, p. 56).

${ }^{8}$ El término red es utilizado en este estudio con tres de sus diversos significados: primero, red como un conjunto de organizaciones que interactúan en la gestión del agua; segundo, como herramienta analítica de la gobernanza y vínculo relacional entre actores; tercero, como la infraestructura de servicios del municipio. La denominación que tiene el Comité Central como "Red del Comité Central de Agua Potable Cuauhtémoc" está referida a la infraestructura hidráulica y no a la articulación de las interacciones entre las organizaciones.
} 
Se encargan también de exigir de los nuevos usuarios una cuota por el derecho a la instalación del servicio. ${ }^{9}$ En las asambleas se decide si los vecinos son candidatos o no a obtener el servicio en función de su colaboración con la comunidad. Para obtener el agua no sólo es necesario cubrir la cuota, es obligatorio realizar trabajo para la comunidad (pintura de banquetas, mano de obra para la construcción de instalaciones públicas o mantenimiento de la infraestructura del servicio). Los requisitos para integrarse a la comunidad generan relaciones afectivas duraderas, pero las colaboraciones monetarias y de participación constante pueden ser un problema para las nuevas formas de configuración de las familias; por ejemplo, los profesionistas trabajadores y empresarios jóvenes se ven limitados para cubrir las exigencias comunitarias que no toman en cuenta los cambios en el estilo de vida, ya que cada vez más mujeres trabajan y no pueden participar en la comunidad de manera asidua, como antes. ${ }^{10}$ Es dentro de esos condicionamientos que los demandantes pueden ser incluidos o excluidos del acceso al agua.

Un acierto generado en los últimos años ha sido la incorporación de mujeres en los CAAP, han participado exitosamente en la gestión y en la incorporación de un lenguaje de sustentabilidad, ya que en las asambleas se hace referencia a la necesidad de pensar las acciones para conservar el agua para los hijos y nietos; en este sentido se han dado emprendimientos para la recuperación de suelos y recarga de acuíferos.

\section{Los nodos y la composición de la red}

Actualmente, la red Sistema de Agua Cuauhtémoc se integra con 30 comités y el comité central; 29 de ellos cooperan para sufragar gastos de operación o mantenimiento y uno lo hace de manera independiente. La red es reconocida por el gobierno municipal como auxiliar para la gestión del agua, aunque no forma parte de la estructura político-administrativa y no está subordinada a las autoridades municipales. El comité central se encuentra integrado por pobladores representantes de los comités autónomos. Entre sus atribuciones está coordinar las decisiones colectivas, promover la convivencia, la participación en faenas y el manejo eficiente del recurso por los comités comunitarios; asimismo, ejerce poderes discrecionales en la asignación de recursos provenientes de otras fuentes y en la administración general de la red. Su influencia y poder derivan de que el gobierno municipal no ha demostrado capacidad para convencer a la población de pagar por el agua, situación en la cual las relaciones entre el ayuntamiento y las comunidades están en permanente tensión.

\subsection{Los actores en la gobernanza de la red}

En la conformación de la red se identifican tres tipos de actores que son relevantes en su configuración y gobernanza: actores gubernamentales, actores sociales y actores privados. Los actores asociados a los diferentes

\footnotetext{
${ }^{9}$ La asignación de costos es variable y discrecional, depende de las decisiones de la comunidad y de los comités, actualmente oscila entre 1000 y 9000 pesos.

${ }^{10}$ Una evidencia de la discrecionalidad es la siguiente: "estuve a dar mi cooperación y me comentaron que van a celebrar las fiestas patrias y de eso eran otros 50 pesos por persona, y que me esperaban para ayudar a adornar" (Entrevista a vecino de la localidad de Tomasquillo, Xalatlaco, septiembre 2016).
} 
niveles de gobierno son: el gobierno federal, el gobierno estatal y el gobierno del municipio. Los actores sociales son las organizaciones comunitarias conformadas por representantes ciudadanos en cada localidad y por los demandantes de los servicios. Los actores privados son empresas mercantiles que participan en el aprovisionamiento y la distribución del recurso.

Cuadro 1. Actores en la gobernanza de la red

\begin{tabular}{|c|c|c|}
\hline \multicolumn{2}{|r|}{ Actores } & \multirow{2}{*}{ Funciones/Influencia } \\
\hline Tipo & Denominación & \\
\hline \multirow{4}{*}{ Político } & $\begin{array}{l}\text { Gobierno Federal. Comisión Nacional } \\
\text { del Agua }\end{array}$ & $\begin{array}{l}\text { Establece directrices generales para la gestión del agua y } \\
\text { aporta recursos para la sustentabilidad. }\end{array}$ \\
\hline & Gobierno de la Ciudad de México & $\begin{array}{l}\text { Interviene en conflictos de límites territoriales del área } \\
\text { metropolitana. }\end{array}$ \\
\hline & $\begin{array}{l}\text { Gobierno del Estado de México. } \\
\text { Comisión del Agua del Estado de } \\
\text { México }\end{array}$ & Mediador en los conflictos ambientales y sociales. \\
\hline & Gobiernos municipales & $\begin{array}{l}\text { Son las instancias que legalmente deben proveer el } \\
\text { servicio, reciben las demandas de la población. }\end{array}$ \\
\hline \multirow{4}{*}{ Social } & Comités Autónomos de Agua Potable & $\begin{array}{l}\text { Gestionan el agua doméstica y coordinan su provisión a las } \\
\text { comunidades. }\end{array}$ \\
\hline & Usuarios/Habitantes & Demandan el servicio de agua \\
\hline & Comisariado de Bienes Comunales & $\begin{array}{l}\text { Regula la propiedad comunal y contribuye en actividades } \\
\text { relacionadas con recursos naturales. }\end{array}$ \\
\hline & Instituciones Académicas & $\begin{array}{l}\text { Desarrollan proyectos que contribuyen a la salud o cultura } \\
\text { del agua. }\end{array}$ \\
\hline \multirow{3}{*}{ Privado } & Piperos (privados) & Particulares que venden el agua en las comunidades. \\
\hline & Empresas locales en operación & $\begin{array}{l}\text { Demandan agua y descargan contaminantes a los cuerpos } \\
\text { de agua. }\end{array}$ \\
\hline & Empresas locales de agua potable & Embotellan y venden agua en garrafón. \\
\hline
\end{tabular}

Fuente: elaboración propia con datos de trabajo de campo.

El papel que juegan los actores gubernamentales resulta crucial en la configuración de la gobernanza: El Gobierno Federal, a través de la Comisión Nacional del Agua (Conagua) instrumenta y financia proyectos con los gestores de agua: capacitación, asesoría técnica, monitoreo de la calidad del agua y recursos para la renovación de la infraestructura. ${ }^{11}$

El Gobierno del Estado de México, interviene en dos sentidos: primero, regula el impacto ambiental y, segundo, es mediador en los conflictos por el uso de los recursos naturales.

\footnotetext{
${ }^{11}$ El comité central de agua potable de Xalatlaco, ha aplicado recursos en la renovación de infraestructura de la red de conducción hacia el hospital regional y para la comunidad de Tomasquillo.
} 
El gobierno municipal es el actor clave, ya que desde la descentralización del manejo y la administración del agua en el país, en los años ochenta, los municipios han aumentado sus responsabilidades y su intervención. En el caso de los municipios afectados por el Sistema Lerma, entre los que se encuentra Xalatlaco, los gobiernos municipales son mediadores frente a las demandas y conflictos con las localidades. ${ }^{12}$ Es notable que Xalatlaco no cuente con un Organismo Público Descentralizado Municipal de Agua, Alcantarillado y Saneamiento, sino con una Regiduría de Agua. ${ }^{13}$ El gobierno municipal no dispone de la infraestructura necesaria para la regulación y operación del servicio, por ello es que las organizaciones comunitarias son poderosas en mayor o menor medida.

Los actores sociales intervienen en momentos distintos del proceso de provisión de agua, y son: los Comités Autónomos de Agua Potable, los usuarios o beneficiarios, el comisariado de bienes comunales y las instituciones académicas. Por principio, los CAAP se han convertido en instancias centrales en el manejo del agua; sin embargo, cada uno se integra de manera peculiar, por lo que es complicado encontrar patrones unificados en su estructura y en su gestión.

Los usuarios son los demandantes de agua. Si bien participan en la gestión, la mayoría de las veces se encuentran en constante conflicto con las organizaciones que operan el servicio. Su papel es crucial, ya que aprovechan y son responsables del uso adecuado del recurso, o bien, desperdician, contaminan y hacen mal uso. En el estudio se observan pocos esfuerzos por lograr que los usuarios moderen su consumo y se encontró infraestructura doméstica deficiente para la sustentabilidad del agua.

Otros actores comunitarios, como el Comisariado de Bienes Comunales, vigilan el cumplimiento de las decisiones tomadas en asamblea por los habitantes; importan porque en el municipio persisten problemas en relación directa con decisiones de conservación del bosque, que inciden en la disponibilidad de agua.

El municipio cuenta con la Universidad de Estudios Superiores de Xalatlaco, los comités señalan que ha habido poca intervención de esta y otras instituciones académicas; en ocasiones sus estudiantes realizan el servicio social o sus prácticas profesionales en apoyo a los CAAP.

Los actores privados pueden diferenciarse en: piperos, empresas locales en operación y empresas de agua potable. Los piperos son empresas particulares que se encargan de cubrir las necesidades de agua en localidades que carecen del servicio, o que temporalmente no lo tienen, con costos variables que se estiman elevados para los

\footnotetext{
12 El sistema Lerma es la obra que provee de agua a la Ciudad de México, cuya extracción afecta una región integrada por 17 municipios, lo cual genera diversos conflictos en las localidades.

${ }_{13}$ Los Organismos Públicos Descentralizados de Agua (ODAPAS) constituyen la figura que prescribe la legislación mexicana para regular y operar la gestión del agua.
} 
ingresos de los pobladores, y obtienen ganancias por la comercialización ${ }^{14}$. Adicionalmente, no están regulados y no cuentan con monitoreo de la calidad del agua que distribuyen. Las empresas locales en operación son aquellas instaladas en el municipio, por un lado demandan agua y por el otro contaminan con sus desechos. Por último, están las empresas de agua potable que se encargan de la venta de agua por medio del llenado de garrafones, a un precio menor al de las grandes empresas, demandan grandes cantidades de agua y la comercializan.

\subsection{Los nodos en la gobernanza de la red y la orientación de las relaciones}

La red de gestores se encuentra constituida por los CAAP, el comité central y cuatro organizaciones que obtienen agua por gravedad (figura 1). Las comunidades se encuentran distribuidas en el municipio, sobre todo en territorio urbano, y participan de manera activa en los procesos de toma de decisiones, vigilancia y sanción de los comités. Los representantes de los comités se reúnen bimestralmente para tratar temas generales de la red, los nuevos proyectos, recursos y gastos, y de manera extraordinaria para tratar asuntos imprevistos.

Figura 1. Red de organizaciones comunitarias de agua potable de Xalatlaco.

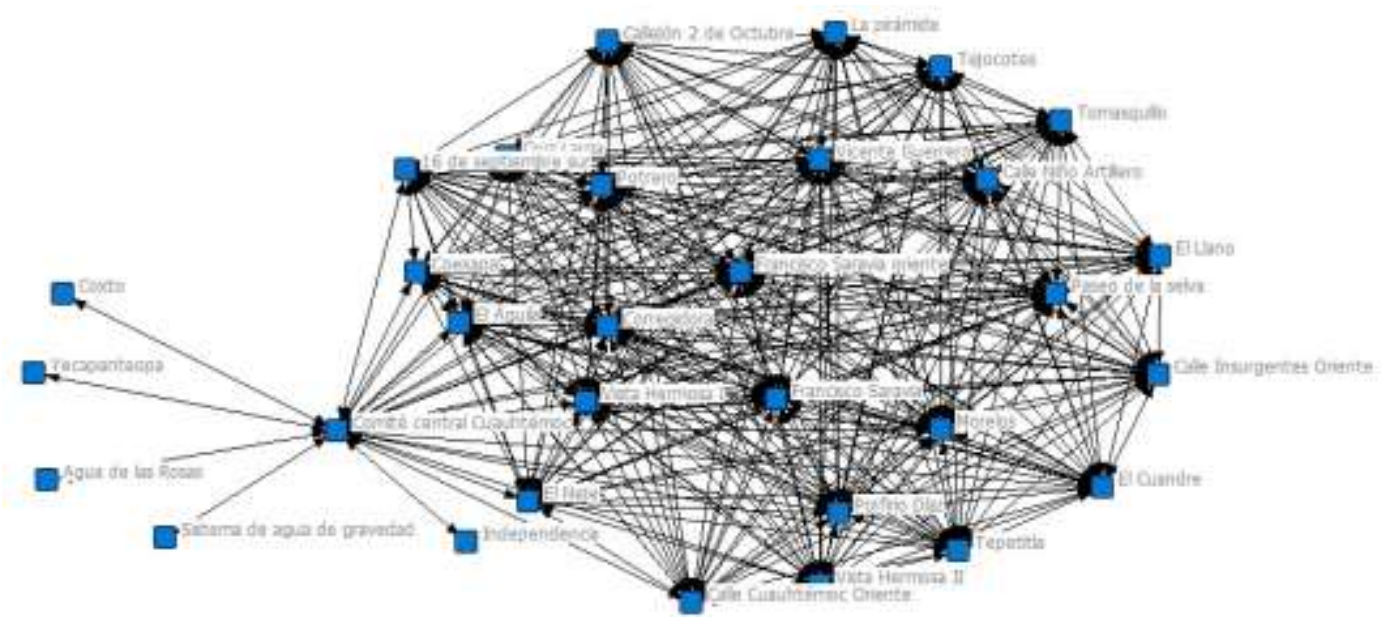

Fuente: elaboración propia con datos de entrevistas a representantes de las organizaciones.

En el esquema de relaciones de la red se observa que los nodos, si bien tienen vínculos con el comité central, también los establecen entre ellos con relativa autonomía, se conforma así un sistema no jerárquico de mayor horizontalidad, que apunta a decisiones consensuadas entre los nodos y de coordinación para la operación general del sistema. ${ }^{15}$ En el trazo se aprecian cuatro organizaciones con menores vínculos con la red en general, el trabajo de campo confirma que son independientes en cuanto a la toma de decisiones y la realización de proyectos.

\footnotetext{
${ }^{14}$ Los piperos pueden ser actores privados o provisores públicos asignados por el ayuntamiento, o formar parte de los CAAP para realizar una función compensatoria a las carencias, dotar de agua a las obras públicas, a las escuelas y hospitales.

15 El funcionamiento de las redes es importante para saber por qué se obtienen ciertos resultados, Putnam distingue entre dos formas de redes. Las redes horizontales reúnen agentes de estatus y poder equivalentes, tienen capacidad para transmitir información entre los miembros de la red, crean incentivos y capital social para comportarse de manera confiable; las verticales vinculan agentes desiguales en relaciones asimétricas de jerarquía y dependencia. Las redes de participación civil con interacciones densas y horizontales acarrean más efectos benéficos a la sociedad (Putnam, 1995).
} 
La red más densa está conformada por el sistema de agua potable "Cuauhtémoc", comprende sólo a comités que tienen agua por bombeo. ${ }^{16}$ Los CAAP que territorialmente se encuentran cercanos tienen relaciones constantes, proyectos en conjunto e incluso participan en acciones de sustentabilidad (figura 2).

Figura 2. Red del sistema "Cuauhtémoc".

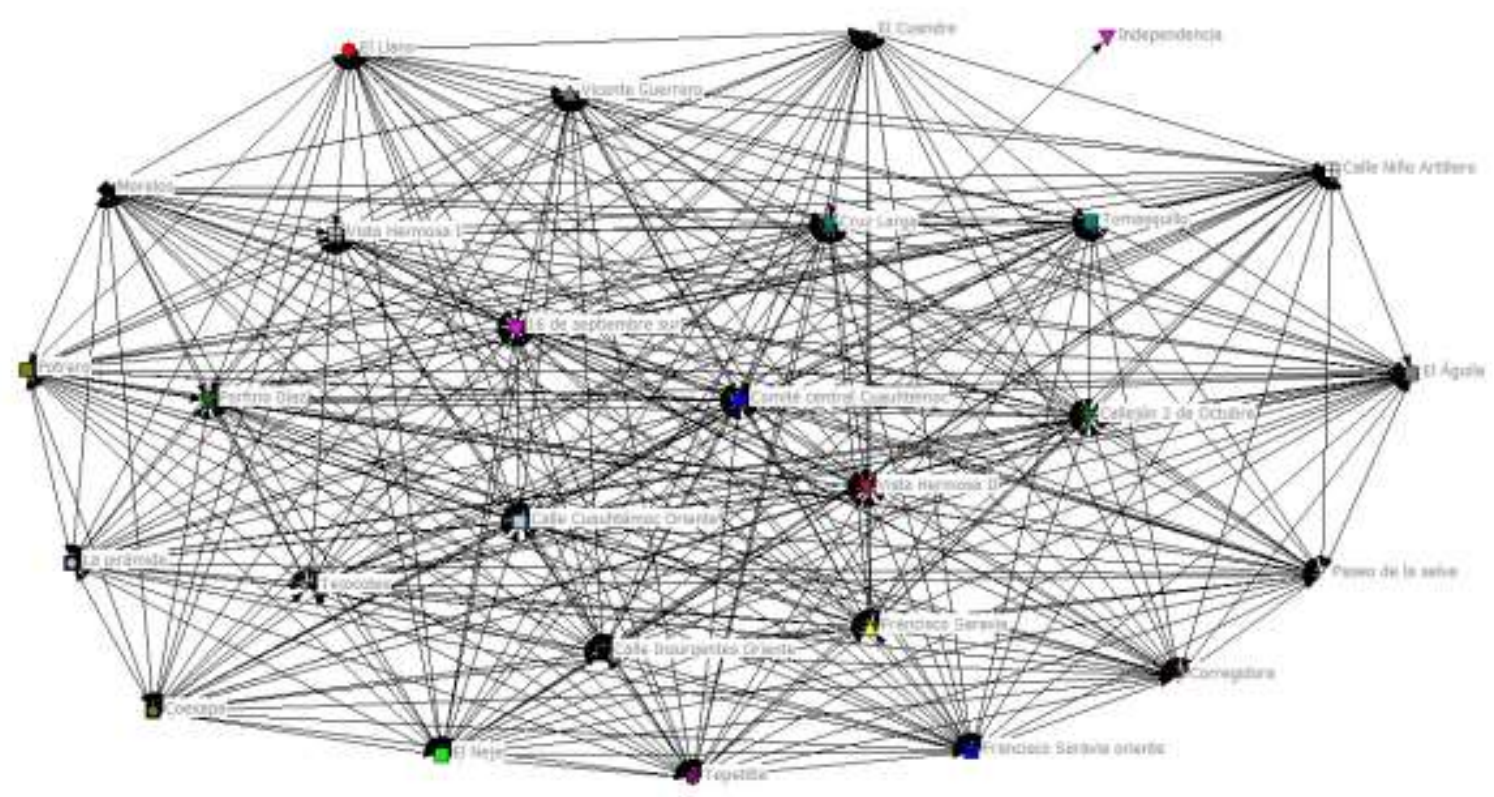

Fuente: elaboración propia con datos de entrevistas a representantes de las organizaciones.

La exploración documental muestra el proceso de institucionalización de esta organización como líder o coordinadora de la red. El Comité central se estableció en el transcurso de varias administraciones municipales. El primer impulso para su constitución provino de las autoridades municipales; el Ayuntamiento convocó a los representantes de las organizaciones comunitarias para proponerles la integración de un comité que se encargara de mejorar el servicio de agua en la localidad con un proyecto general de desarrollo. Posteriormente, la intervención del municipio perdió relevancia, los CAAP se apropiaron del proyecto generando nuevas relaciones y diversificando los actores, con mayor autonomía; pero también se apartaron del proyecto general y se fortalecieron las atribuciones del comité central.

En la figura 3 se observa la centralidad del comité como nodo de coordinación de los CAAP, que lo convierte en el mediador con actores gubernamentales y organizaciones externas, sus representantes son percibidos por la sociedad como depositarios de prestigio, eso contribuye a que el comité sea una organización con poder. ${ }^{17}$ La centralidad en este caso no implica la verticalidad y la jerarquía de las decisiones, se ubica más bien en el ámbito de la representación colectiva.

\footnotetext{
${ }^{16}$ La densidad es un indicador de conectividad referido al número de relaciones existentes (Velázquez y Aguilar, 2005, p. 20).

${ }^{17}$ La centralidad de un actor está representada por el número de otros actores a los cuales un actor está directamente conectado por un vínculo (Velázquez y Aguilar, 2005).
} 
Figura 3. Centralidad del comité de agua potable "Cuauhtémoc".

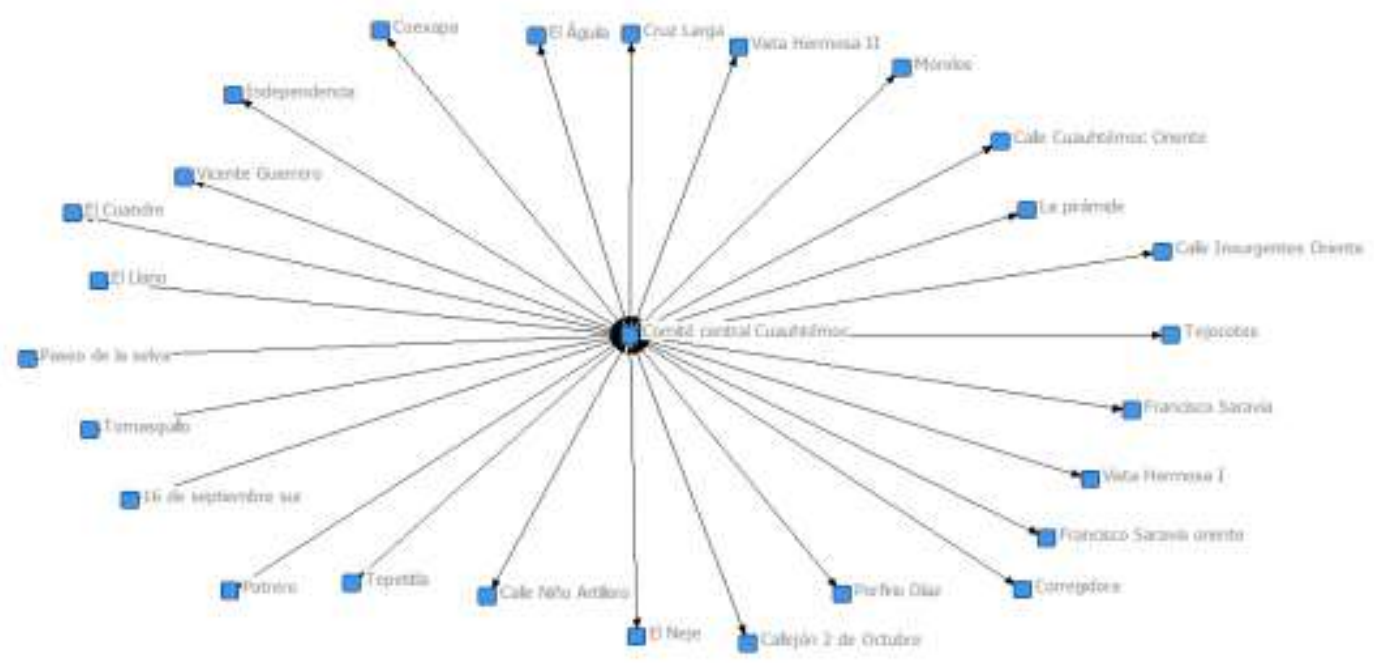

Fuente: elaboración propia con datos de entrevistas a representantes de las organizaciones.

\subsection{La gobernanza externa de las organizaciones gestoras}

Para la ejecución de los proyectos de gestión de agua es necesario establecer relaciones cooperativas que permitan transitar minimizando el conflicto. Los arreglos de gobernanza tienen que ver con la autonomía de los comités, percibida como la no injerencia de agentes externos en la toma de decisiones. En la red participan como actores externos: el gobierno municipal, la Conagua, la Comisión del Agua del Estado de México (CAEM), los Comités Ciudadanos de Control y Vigilancia (COCICOVIS) $)^{18}$ y el Comisariado de Bienes comunales (figura 4).

Figura 4. Comité central de agua y su entorno.

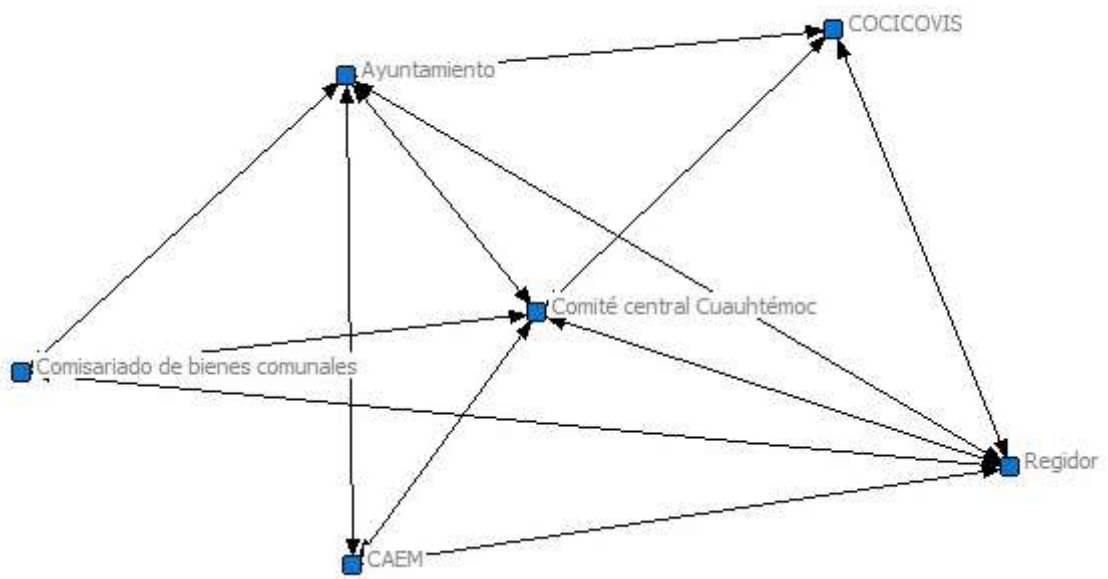

\footnotetext{
18 Los Comités Ciudadanos de Control y Vigilancia (COCICOVIS), son organizaciones integradas por contralores sociales elegidos por la comunidad y cuya actuación se orienta a vigilar la correcta aplicación de los recursos públicos. En el caso de Xalatlaco están conformados en la cabecera municipal, en las localidades cubren esas funciones los delegados municipales.
} 
Fuente: elaboración propia con datos de entrevistas a representantes de las organizaciones.

El Ayuntamiento aporta materiales y facilita la gestión de permisos para realizar obras públicas; en diversos momentos, el gobierno municipal también recibe ayuda de los CAAP para la concreción de proyectos y obras. Asimismo, se realizan acciones con la participación de los COCICOVIS. La CAEM se encarga del monitoreo del agua en puntos del municipio, formula recomendaciones y/o apoya con recursos técnicos la mejora de la calidad del agua. El Comisariado de Bienes comunales, participa en actividades cotidianas y otras como marchas, mítines y eventos. Como puede observarse los comités no son totalmente autónomos, son interdependientes en las relaciones cooperativas con los agentes externos. Se observa en la figura 5 la integración de las relaciones internas con los actores externos.

Figura 5. Red de actores internos y externos en la gestión del agua.

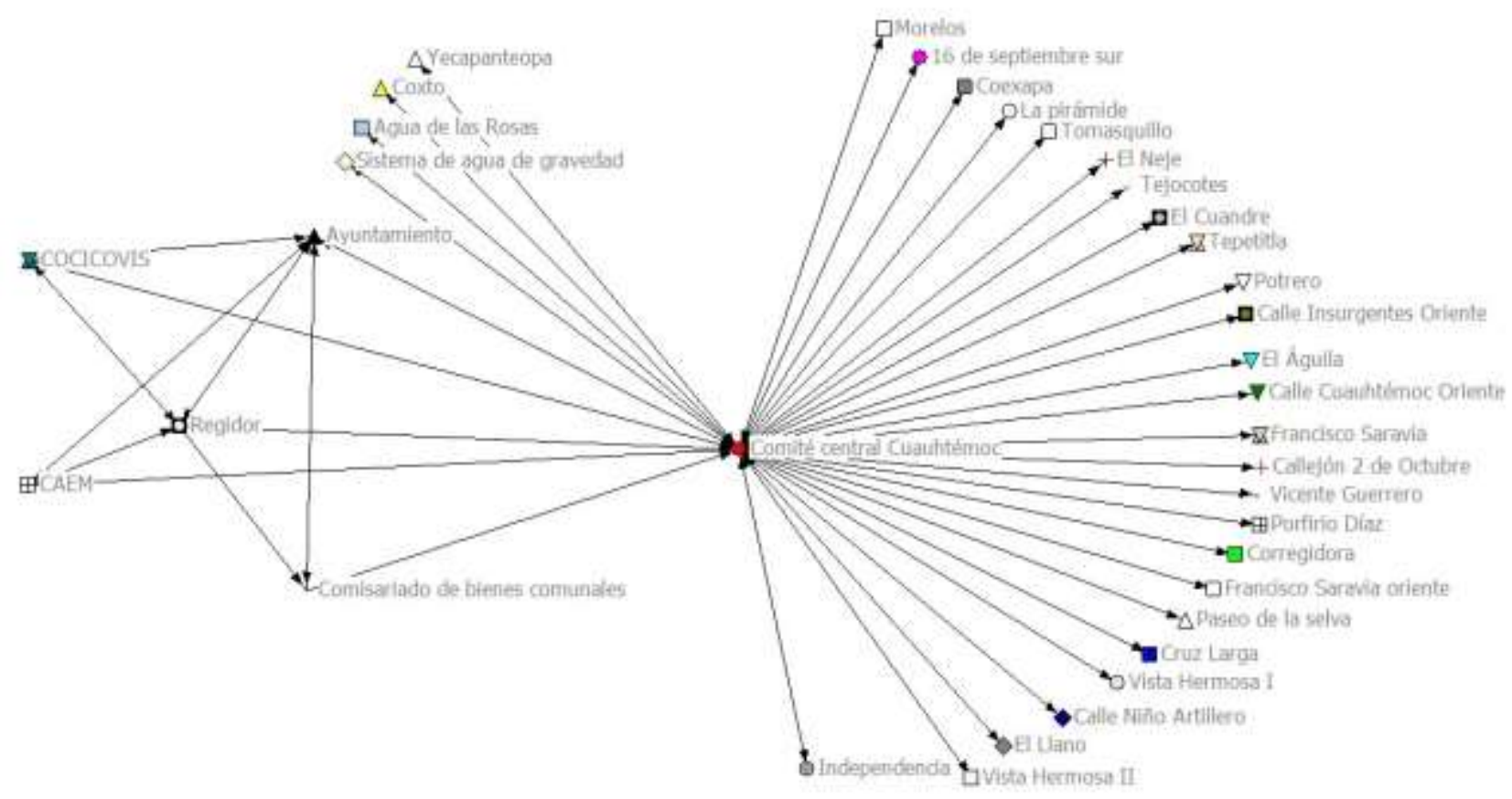

Fuente: elaboración propia con datos de entrevistas a representantes de los CAAP.

De datos complementarios se infiere que se registra una tendencia en el municipio hacia la privatización y mercantilización del agua, no solamente a través de la expansión de empresas comerciales o de las pipas de agua, sino en el incremento del consumo de agua embotellada y la venta de terrenos con presumible abastecimiento de agua que es extraída del subsuelo para la realización de actividades industriales. Otros datos marcan el cambio de esquemas relacionales que vinculaban a los usuarios con el cuidado del recurso, hacia otros que toleran el extraccionismo hídrico, a costa del desmembramiento progresivo de las estructuras, capacidades de autogestión y solidaridad mutua entre barrios, comunidades y pueblos (Navarro, 2015). Existe entonces una creciente desterritorialización, en el sentido que los beneficiarios del recurso se desprenden de los elementos simbólicos y de identidad con el origen del agua que consumen. 


\subsection{Los mecanismos de inclusión-exclusión en la gestión del agua}

La exclusión, una noción opuesta a la inclusión, es un concepto polisémico sujeto a múltiples interpretaciones: puede significar estar fuera del sistema productivo, no participar de los beneficios del desarrollo económico, o estar fuera de las redes sociales (Castel, 2004). ${ }^{19}$ Aquí se tocan algunos de esos significados, pero el concepto utilizado refiere simplemente a los mecanismos instrumentados por las organizaciones que permiten o no tener acceso a la provisión de agua; no se deja de lado que la exclusión se traduce en la privación del ejercicio de un derecho y en estar fuera de redes de sociabilidad comunitaria. ${ }^{20}$

Del camino seguido por una solicitud para obtener agua se sabe que en los Comités radican las determinaciones sobre quienes pueden ser incluidos y que las decisiones consideran aspectos de territorialidad, regionalización, pertenencia e involucramiento de los demandantes con las actividades comunitarias. En forma no menos importante, tienen que ver con los costos por el servicio y con la institucionalización de ciertas prácticas. Para examinar estos componentes de la gobernanza se presentan los resultados de la exploración organizados en: Identidad y pertenencia, autonomía política, autonomía económica y mecanismos de inclusión y exclusión. ${ }^{21}$

\subsubsection{Identidad y pertenencia}

La pertenencia es una cuestión de reconocimiento mutuo o compartido entre el grupo y sus miembros, es la forma aceptada en que unas personas se presentan a otras (Margalit, 1997, p. 117). La pertenencia es importante en los procesos de inclusión-exclusión, porque se traduce en aceptación o rechazo. La aceptación se concreta como acceso al recurso y el rechazo como exclusión. Se rechaza no solamente al solicitante, sino al grupo al que esa persona pertenece (por ejemplo, no nacidos en la comunidad o nuevos moradores). El rechazo o la imposición de condiciones de aceptación pueden ser humillantes. La pertenencia conlleva que se comparten valores, tradiciones, rituales, ceremonias, que permiten que el grupo se identifique y distinga de otros (Margalit, 1997). La identidad es la vertiente subjetiva de la pertenencia que se configura como una interiorización de la posición y el papel adquiridos socialmente.

Los datos muestran que el acceso al agua se apoya en una percepción fuerte de identidad y pertenencia comunitaria. La prestación se percibe como un derecho que otorga la comunidad y como un derecho de nacimiento, no como un derecho de los demandantes. Es interpretada como sentido de arraigo al territorio y a la comunidad. La mayoría de los pobladores no cambiaría de domicilio, cuentan con sólidos vínculos de pertenencia, señalando que es

\footnotetext{
${ }^{19}$ Margalit (1997) considera que la inclusión implica la existencia de un conjunto de relaciones sustentadas en el reconocimiento y la pertenencia a grupos o sectores sociales. Un grupo incluyente puede ser una nacionalidad, una cultura común, un lenguaje, una profesión, un oficio.

${ }^{20}$ Los mecanismos son parte articuladora de los procesos, entendidos como causas o eventos que producen efectos similares en una variedad de circunstancias y a partir de los cuales es posible explicar los fenómenos sociales (Brachet-Márquez y Uribe, 2016, p. 24).

${ }^{21}$ Las entrevistas semiestructuradas y la encuesta fueron realizadas a población que es usuaria del sistema "Cuauhtémoc", la mayoría de los entrevistados fueron comerciantes o campesinos.
} 
bueno vivir en el municipio, incluso si surgiera fuera una oportunidad laboral, con mayores ingresos no migrarían (gráfica 1).

Gráfica 1. Disponibilidad a cambiar de domicilio en sectores de población.

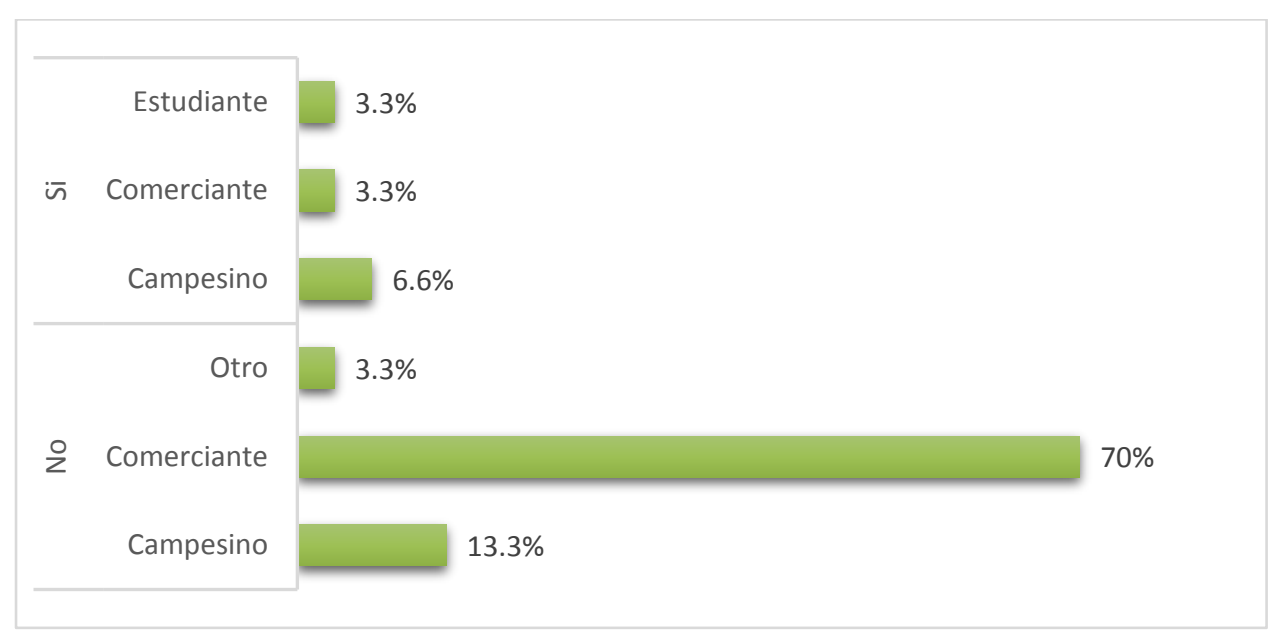

Fuente: elaboración propia, con datos de la encuesta a pobladores de Xalatlaco, 2016.

Se infiere la vinculación de la pertenencia comunitaria con las oportunidades de acceso al agua, ya que son decisiones colectivas, arraigadas en prácticas construidas a través de la residencia y la integración a entornos locales las que determinan la inclusión.

\subsubsection{Autonomía política}

Los resultados de los CAAP derivan de su interacción con otros actores y de la aceptación comunitaria, para ser exitosos requieren de acuerdos con actores políticos, autoridades y personas que representan diversos intereses, pueden ser entonces sujetos de presiones políticas que vulneren su autonomía. Los datos obtenidos señalan la presencia de un sector de usuarios que piensan que la responsabilidad de otorgar el agua es competencia del Ayuntamiento; y otro que es responsabilidad del CAAP. Sobre las responsabilidades de los usuarios y las acciones que limitan su acceso, la mayoría respondió que se les restringe el acceso por el incumplimiento en las cuotas o por no asistir a la asamblea (gráfica 2). Las asambleas pueden convertirse entonces en mecanismos de control político. Finalmente, la mayoría de los entrevistados opina que el manejo del agua realizado por los CAAP es regular o bueno, lo que legitima su gestión (gráfica 3). 
Gráfica 2. Responsabilidades y limitantes de acceso al agua.

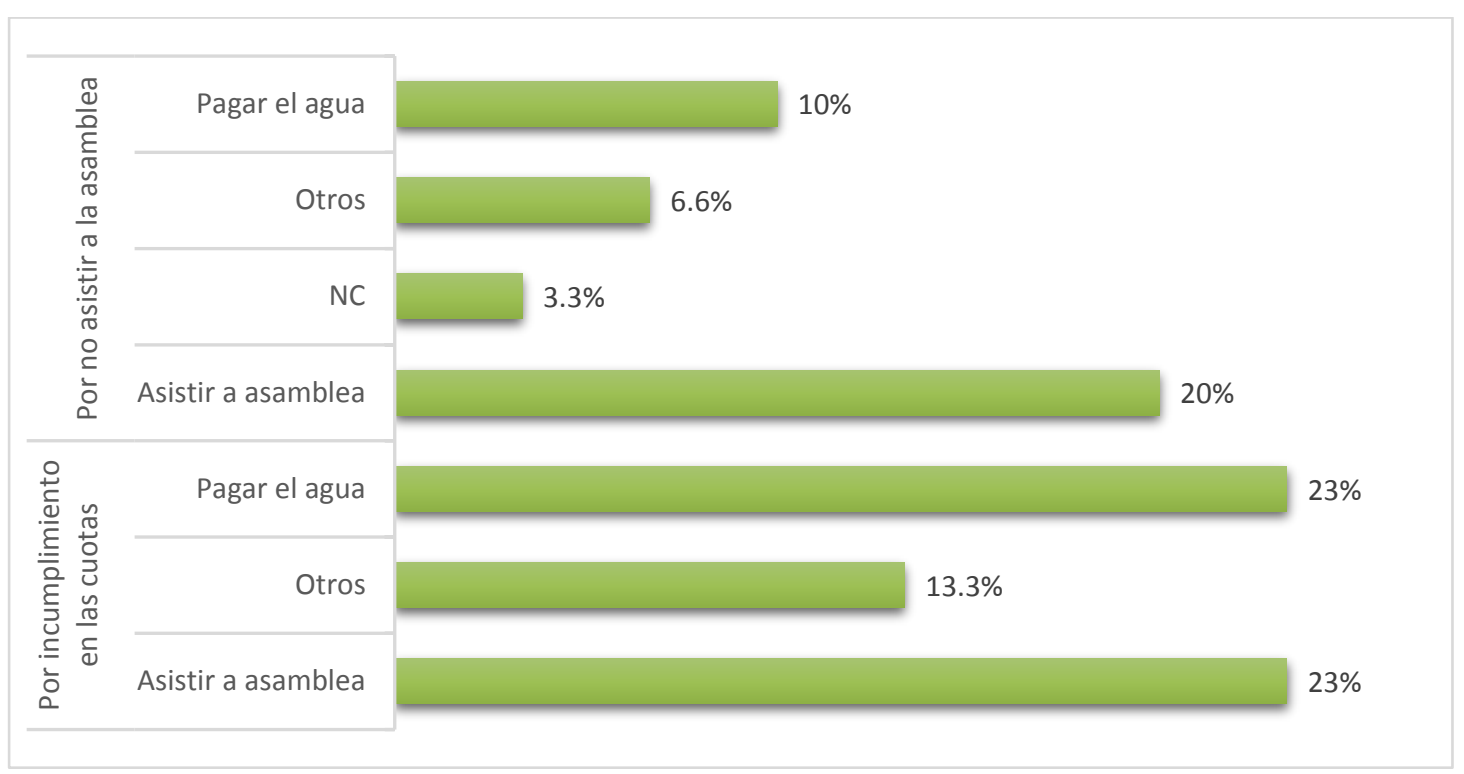

Fuente: elaboración propia, con datos de la encuesta a pobladores de Xalatlaco 2016.

Gráfica 3. Evaluación de la gestión del comité central por sexo

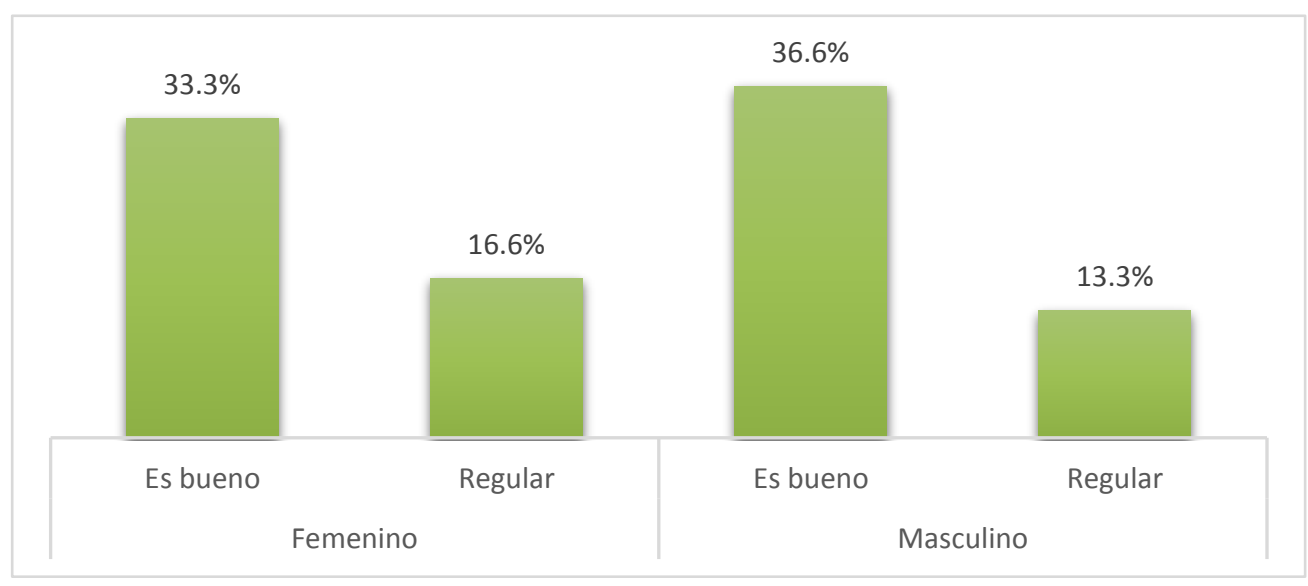

Fuente: elaboración propia, con datos de la encuesta a pobladores de Xalatlaco 2016.

Así la percepción comunitaria se interpreta como acuerdo con el poder de los comités. No obstante, desde otros ángulos se nota que su autonomía es limitada, ya que sin la injerencia y apoyo de agentes externos estarían imposibilitados de ampliar los servicios, corregir fallas y garantizar la provisión a los usuarios. ${ }^{22}$ Es decir existen arreglos de gobernanza que respaldan la operación de los CAAP.

\footnotetext{
22 En 2016 se realizó la pavimentación de $17.271 \mathrm{~m}^{2}$ en el municipio con recursos del programa federal de Acciones para el Desarrollo (PAD), con obras de mantenimiento y actualización de la Red de Agua Potable, y se destinaron $206.000,00$ pesos del Fondo para la Infraestructura Social Municipal y de las Demarcaciones Territoriales del Distrito Federal (FISMDF) para la construcción de un almacén de agua potable.
} 


\subsubsection{Autonomía económica}

Los CAAP cuentan con ingresos directos por pagos de los usuarios, cada uno recolecta el pago y lo transfiere al comité central, que destina a mantenimiento general de la red y al pago de electricidad para el rebombeo. Los representantes y directivos de los CAAP no tienen salario, pero los integrantes del comité central detentan un salario simbólico por parte del Ayuntamiento. La mayoría de la población estima que la calidad del servicio es buena y están dispuestos a continuar con el pago por la administración del agua (gráfica 4).

Gráfica 4. Opinión sobre la calidad del servicio.

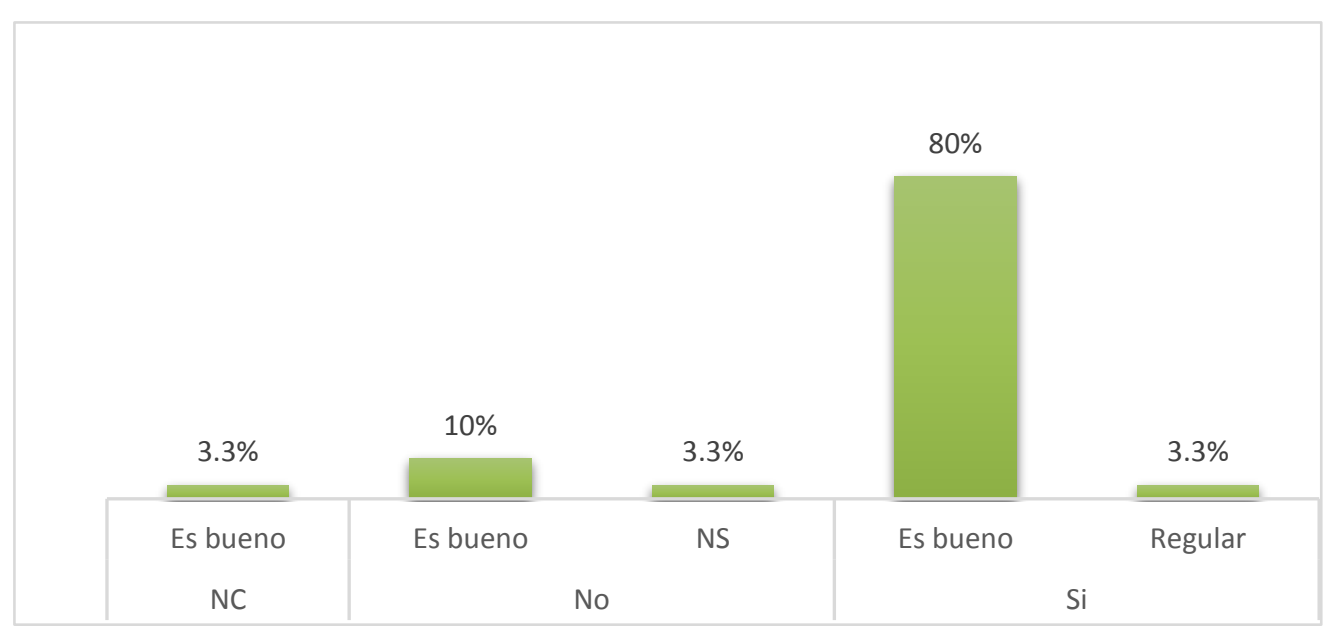

Fuente: elaboración propia, con datos de la encuesta a pobladores de Xalatlaco 2016.

Los mecanismos que amplían o restringen la autonomía económica y por consecuencia la expansión y calidad de los servicios son los subsidios, la rendición de cuentas sobre los recursos de origen público y el monitoreo de agentes externos.

\subsubsection{Criterios de inclusión-exclusión}

Cuando las personas llegan al municipio, se asientan en una localidad y demandan el servicio; el otorgamiento de agua depende generalmente de tres criterios: la participación en la comunidad, el pago de la cuota que se solicita y el lugar de origen. El primero, se puede dar en el transcurso de su estancia en la comunidad, con el requerimiento de participar en actividades comunitarias y con la percepción colectiva de que se integran pacíficamente a la vida cotidiana del lugar; el segundo y tercero tienen que ver con el lugar de origen, si las personas o los padres son originarios del municipio, los pagos son menores y la transición de ser ajeno a la comunidad a ser parte de ella, es más fácil; en caso contrario, si las personas vienen de otros lugares y no cuentan con lazos sanguíneos o con familiares que radiquen en la localidad, los pagos pueden ser altos, y el otorgamiento de agua puede no darse en varios meses o incluso años. 
En ese marco general existen diferencias, se advierte que el acceso al agua en el centro del municipio es más asequible; en la mayoría de los casos, a una solicitud se responde positivamente otorgando el agua en plazo breve. Cuando se formula desde las comunidades, los demandantes pueden tardar años en lograr la toma (gráfica 5).

Gráfica 5. Actores decisionales y criterios de inclusión.

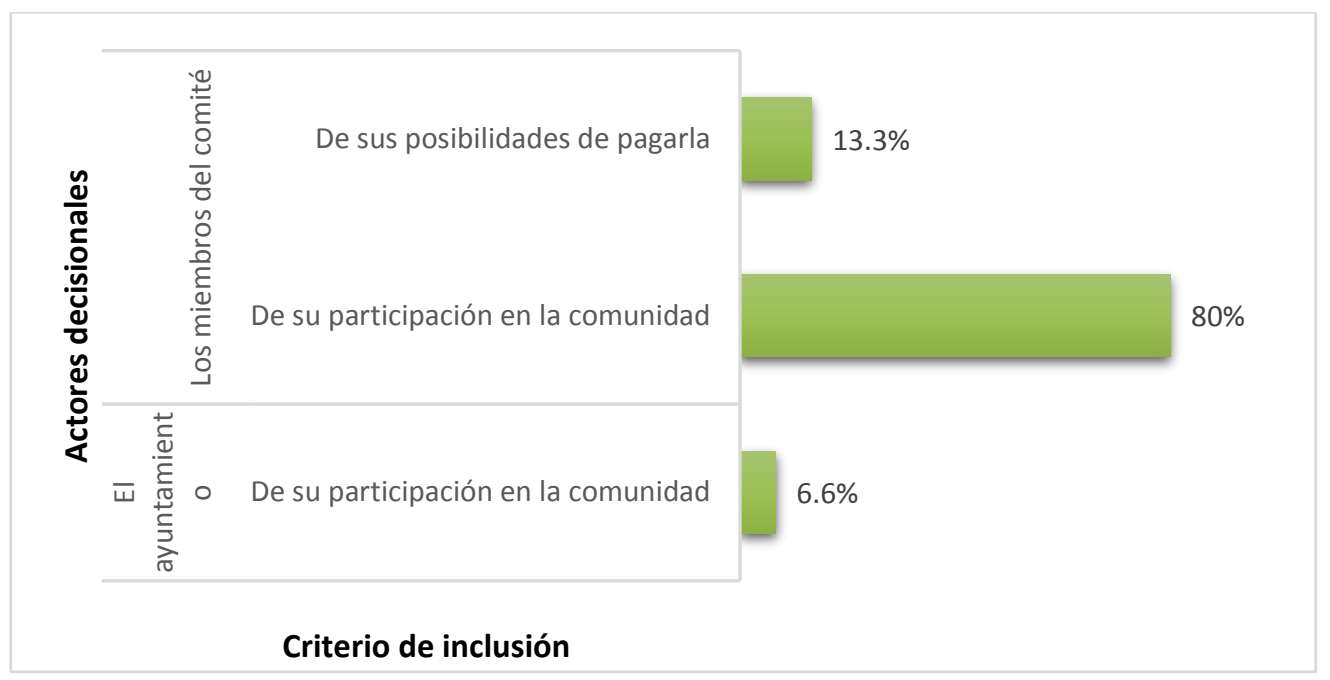

Fuente: elaboración propia, con datos de la encuesta a pobladores de Xalatlaco 2016.

La mayoría de la población conoce las sanciones e identifica que estas son económicas o sociales: los costos para los que no cubren los requisitos son mayores, no se les elige como representantes o se les excluye del servicio (gráfica 6).

Gráfica 6. Conocimiento de la comunidad sobre tipo de sanciones a usuarios.

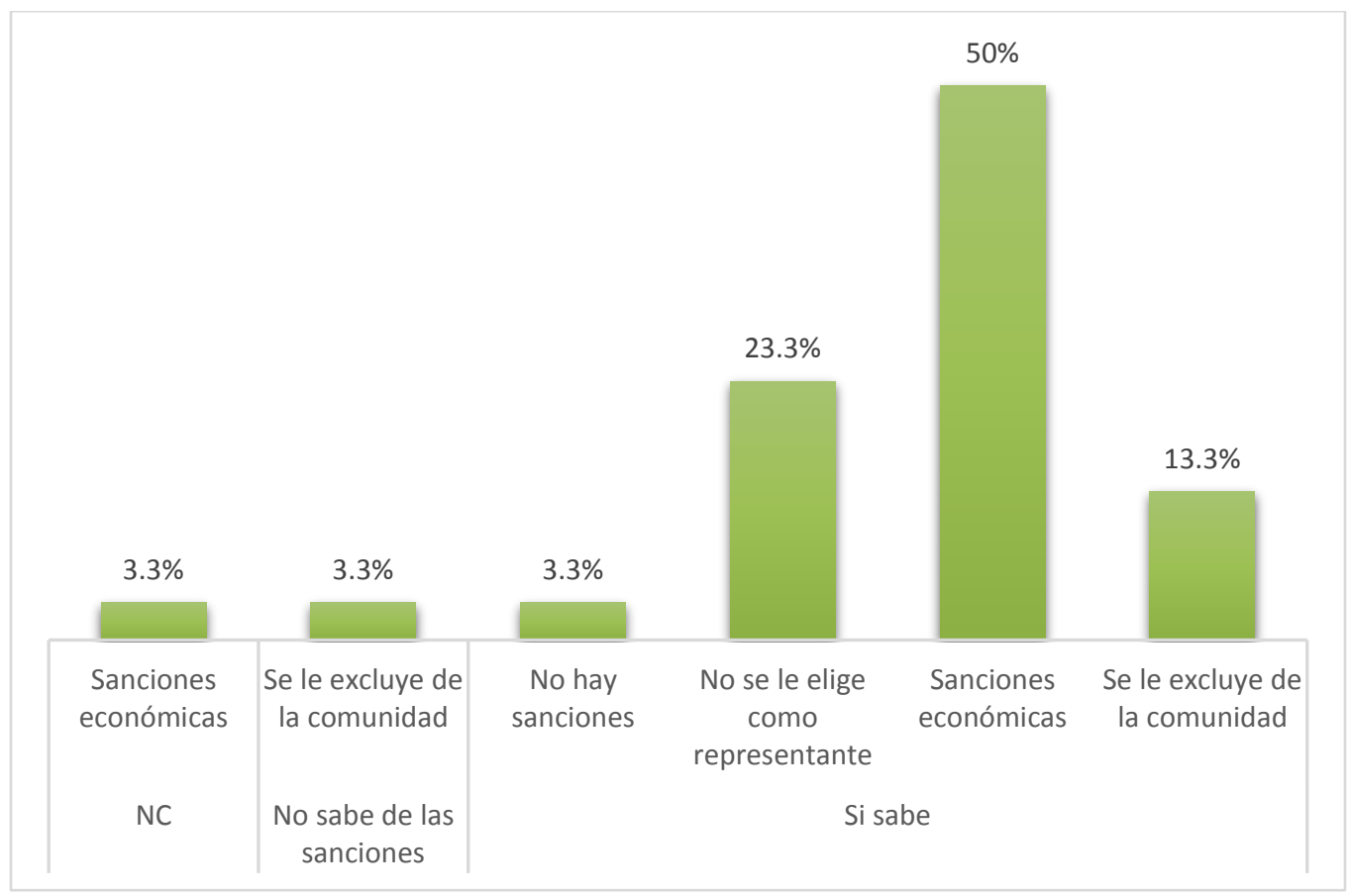

Fuente: elaboración propia, con datos de la encuesta a pobladores de Xalatlaco 2016. 
Los mecanismos de inclusión-exclusión son: la asamblea comunitaria, las reglas comunitarias formales e informales y los criterios discrecionales de los directivos de los CAAP.

Con esos elementos se puede concluir que el acceso al agua como recurso común y bien público enfrenta problemas: por una parte, como sucede con la propiedad privada, los directivos de los comités cuentan con prerrogativas de excluir o elevar su costo a demandantes que carecen de derechos de pertenencia, o a quienes se estima, discrecionalmente, no cumplen con compromisos y prácticas comunitarias y; por otra parte, tales decisiones vulneran derechos asociados a la satisfacción de necesidades básicas para el bienestar de la población. ${ }^{23}$

\section{Reflexiones Finales}

Hace algunos años, las organizaciones comunitarias referían la abundancia del agua que existía en Xalatlaco, incluso había lugares donde no se podían cerrar las mangueras de agua porque la presión hacía que reventaran, así es que se dejaba correr el agua. Actualmente, las mismas organizaciones atestiguan el incremento de la demanda y de manera paralela la disminución del agua en los manantiales. Esas preocupaciones han tenido repercusiones en la conducta de los actores que intervienen en la gestión del agua. Así, en el lenguaje de los involucrados ya se encuentran las palabras: sustentabilidad, insuficiencia, cuidado del agua, lo que habla de una conciencia diferente, acompañada de la visión de sancionar la contaminación y el desperdicio, acciones que están en discusión en la agenda de las organizaciones.

En el marco de esa transformación, las relaciones campo-ciudad se han visto como posiciones dicotómicas y contrapuestas, que provocan conflictos en las relaciones entre los pobladores. El estudio de caso evidencia no solamente las transformaciones del espacio periurbano, donde convergen el campo y la ciudad, sino que deja ver intereses contradictorios y en pugna por los recursos existentes. Es claro, por ejemplo, que los criterios de acceso no se corresponden con las características del desarrollo, la urbanización y la metropolización del municipio.

Destaca la relevancia de la intervención de las organizaciones comunitarias en la gestión de agua, otorgan un servicio que nadie (en este caso el ayuntamiento) puede dar $\mathrm{y}$, de manera vertiginosa, en un lapso de tres décadas han visto crecer sus responsabilidades y su influencia. Así, en los complejos procesos de transformación del sistema socioeconómico, político y del entorno ambiental, los arreglos de gobernanza que construyen los actores sociales poseen un gran número de elementos activos y de relaciones, de las cuales aquí se han identificado solamente las ligadas a las formas de gestión comunitaria de la provisión de agua; ello deja pendiente una mirada más amplia sobre el sistema socioecológico y su sustentabilidad, del cual es parte el manejo del agua.

\footnotetext{
${ }^{23}$ El dilema refiere al planteamiento de Ostrom en el sentido de que la propiedad colectiva (como puede ser el caso de las comunidades u organizaciones que se asumen dueñas del agua) es en realidad propiedad privada colectiva; porque a diferencia de la propiedad pública, existen titulares de derechos y obligaciones reconocidos y ellos cuentan con el derecho de excluir a otros del acceso a los bienes (Merino, 2014, p. 85).
} 
Entre los problemas evidentes de la gestión comunitaria destaca que no existe, al menos en los CAAP examinados, el acceso sin restricciones; al parecer en las comunidades alejadas es donde existen mayores limitantes y éstas no siempre son monetarias. A pesar de ello, la percepción sobre la gestión de las organizaciones comunitarias es positiva, lo que legitima los arreglos de gobernanza establecidos. Entre los hallazgos relevantes se anota que, además del fortalecimiento de sus capacidades, los comités han logrado acumular experiencia, mejorar la gestión e impulsar el manejo sustentable del recurso mediante alianzas con otras organizaciones. Se evidencian elementos de cooperación y participación recíproca que contribuyen a la gobernanza y a la sustentabilidad.

Otra práctica positiva radica en la apertura de los comités a nuevas redes de convivencia; posiblemente como una derivación de los cambios generados por el incremento de la escolaridad en sus integrantes, la integración de la tecnología a la vida cotidiana de las organizaciones y el contacto con nuevos actores que potencializan sus capacidades. Han logrado también que las autoridades los reconozcan como instancias de participación en la provisión del recurso y que ejerzan funciones de regulación. Esos arreglos de gobernanza tienen repercusiones positivas y negativas en la sustentabilidad, ya que su eficacia está limitada por condicionamientos políticos y por debilidades en sus capacidades de gestión.

Metodológicamente, los hallazgos de la investigación pueden ser descritos a partir de las categorías propuestas. Falta, no obstante, una visión global y amplia de los problemas de sustentabilidad y un estudio detallado de las prácticas llevadas a cabo por los comités comunitarios en las dimensiones estudiadas. Asimismo, si bien la estructura de las organizaciones en forma de cuerpos directivos permanece, es necesario reconocer que también han sido intervenidas por los pobladores, que las han adaptado a sus necesidades, con interacciones cada vez más horizontales y con la intervención de actores que vigilan y en su caso toman decisiones; formas de participación que requieren también de un estudio más profundo.

Finalmente, se identifican en el municipio, cambios socioterritoriales drásticos. En ese contexto, se ha dado un proceso de reacomodo de las formas de gestión donde los gobiernos y las organizaciones se encuentran en constante cambio, y es de reconocer que si bien algunas de sus estrategias se inclinan a la desaparición de organizaciones como los comités comunitarios, otras las impulsan a adaptarse, flexibilizar y mejorar su gestión. En esa dinámica móvil el estudio revela sólo un momento de este proceso. 


\section{Referencias bibliográficas}

AGUILAR, L. F. (2010). El futuro de la gestión pública y la gobernanza después de la crisis. Frontera Norte, 22(43), 187213, recuperado el 26 de octubre de 2016 de:

http://redalyc.uaemex.mx/src/inicio/ArtPdfRed.jsp?iCve=13612035008

AMAYA, M. L. (2010). Acción pública, instituciones y efectividad de los mecanismos de cooperación en el sistema de gestión del agua de Aguascalientes. Gestión y Política Pública,19(1), 37-77. Recuperado el 20 de enero de 2017 de: <http://www.scielo.org.mx/scielo.php?script=sci_arttext\&pid=S1405-10792010000100002\&lng=es\&nrm=iso>.

AYUNTAMIENTO DE XALATLACO (2009). Plan de desarrollo municipal de Xalatlaco 2009-2012. Xalatlaco: Archivo municipal.

BARKIN, D. (2006) Introducción. En Barkin, D. (Coord.). La gestión del agua urbana en México: retos, debates y bienestar. Guadalajara: Universidad de Guadalajara. Recuperado el 26 de octubre de 2016 de:

http://www.agua.org.mx/220--sp-447/-sp-434/1349-la-gestion-del-agua-urbana-en-mexico-retos-debates-ybienestar.

BLANCO I. y GOMÁ, R. (2003). La crisis del modelo de gobierno tradicional reflexiones en torno a la governance participativa y de proximidad. Gestión y Política Pública, XII(1), México: CIDE.

BRACHET-MÁRQUEZ, V. y URIBE, M. (2016). Introducción En Brachet-Márquez, V. y Uribe, M. (Comp.), Estado y sociedad en América Latina. México: El Colegio de México., pp. 9-37.

CASTEL, R. (2004). Las trampas de la Exclusión. Trabajo y utilidad social. Argentina: Editorial Topía.

FLEURY, S. (2002). El desafío de la gestión de las redes de políticas. Instituciones y Desarrollo, 12(13), 221-247, recuperado el 12 de septiembre de 2016 de: http://www.saludcolectiva-unr.com.ar/docs/SC-247.pdf

GUERRERO, A. et al. (2010). Gobernanza y participación social en la gestión del agua en la microcuenca El Cangrejo, en el municipio de Autlán Navarro, Jalisco, México Economía, sociedad y Territorio, X (33), 541-567.

HUFTY, M. (2008). Una propuesta para concretizar el concepto de gobernanza: El marco analítico de la gobernanza. En Mazurek H. (Ed.). Gobernabilidad y Gobernanza en los territorios de América Latina. Recuperado el 18 de enero de 2017

http://graduateinstitute.ch/files/live/sites/iheid/files/sites/developpement/shared/developpement/projets/GREG/pu bl_GREG/MarcoAnalíticoE.pdf

IGECEM, Instituto de Información Geográfica, Estadística y Catastral del Estado de México, (2015). Recuperado el 23 de febrero de 2017 de:

http://igecem.edomex.gob.mx/sites/igecem.edomex.gob.mx/files/files/Archivos\%20PDF/Productos\%20Estadisticos/ \%C3\%8Dndole\%20Econ\%C3\%B3mica/AGENDA\%20ESTAD\%C3\%8DSTICA\%20B\%C3\%81SICA/Agenda\%20Basica\%20Edo \%20de\%20M\%C3\%A9xico\%202015.pdf

INEGI, Instituto Nacional de Estadística Geografía e Informática, (2010). Recuperado el 16 de mayo de 2016 de: http://www.inegi.org.mx/est/contenidos/proyectos/ccpv/cpv2010/Default.aspx

LASCOUMES P. Y LE GALÈS, P. (2014). Sociología de la Acción Pública. (2a. ed.) México: El Colegio de México.

LAVILLE, J. L., YOUNG D. R., y EYNAUD, P. (2015). Introduction to part I. En Laville, J. L., Young D. R., y Eynaud, P. (Edit.). Civil society, the third sector and social enterprise. Governance and democracy. Nueva York: Routledge, pp. 2544. 
MARGALIT, A. (1997). La sociedad decente. Barcelona: Paidós.

MERINO, L. (2014). Perspectivas sobre la gobernanza de los bienes y la ciudadanía. Revista Mexicana de Sociología, 76(E), 77-204.

NAVARRO, M. L. (2015). Luchas por lo común. Antagonismo social contra el despojo capitalista de los bienes naturales en México. Puebla: BUAP.

OSTROM, E. (2014). Más allá de los mercados y los Estados: gobernanza policéntrica de sistemas económicos complejos. Revista Mexicana de Sociología. 76 (E) 15-70.

POTEETE, A., JANSSEN, M., y OSTROM, E. (2012). Trabajar Juntos. Acción colectiva, bienes comunes y múltiples métodos en la práctica. México: UNAM/IASC/CIDE/Colsan/CONABIO/CCMSS/FCE/UAM.

PROVAN, K.G., y KENIS, P. (2008). Modes of Network Governance: Structure, Management, and Effectiveness. Journal of Public Administration Research and Theory, 18(2), 229-252.

PUTNAM, R. D. (1995). Bowling Alone: America's Declining Social Capital. Journal of Democracy, 6, 65-78

RHODES, R. A. W. (2007). Understanding governance: ten years on. Recuperado el 11 de octubre de 2016 de: :https://www.researchgate.net/.../241135456 Understanding Gov

SECRETARÍA DE DESARROLLO URBANO Y VIVIENDA, SEDUV. (2003). Plan municipal de desarrollo urbano 2003, Xalatlaco. Recuperado el 12 de octubre de 2016 de:

http://seduv.edomexico.gob.mx/planes municipales/Xalatlaco/doc-xalatlaco.pdf

SEDESOL, (2010). Diagnóstico: alternativas de la población rural en pobreza para generar ingresos sostenibles. Recuperado el 16 de mayo de 2016 de:

www.sedesol.gob.mx/work/.../SEDESOL/Sedesol/.../diagnostico/Diagnostico POP.pdf

VELÁZQUEZ, O. A. y AGUILAR, N. (2005), Manual introductorio al análisis de redes sociales, Recuperado el 3 de febrero de 2017 de: http://revista-redes.rediris.es/webredes/talleres/Manual_ARS.pdf

VENANCIO, A. e IRACHETA, A. (2015). Gobernanza metropolitana como estrategia para planificar y gestionar el desarrollo de la Zona Metropolitana del Valle de Toluca. Revista de estudios regionales 102. Málaga: Universidades Públicas de Andalucía.

\section{Entrevistas}

Entrevista a usuario, comunidad Tejocotes, abril 2016.

Entrevista a usuario, comunidad de Tomasquillo, Xalatlaco, abril 2016.

Entrevistas a integrantes del cuerpo directivo del Comité central del Sistema "Cuauhtémoc", enero-mayo 2016, Xalatlaco. 